\title{
O LUGAR COMO IMATERIALIDADE DA PAISAGEM CULTURAL
}

THE PLACE AS CULTURAL LANDSCAPE IMMATERIALITY

Soraya Nór*

\section{RESUMO}

$\bigcirc$ presente artigo procura apresentar a noção de paisagem cultural, compreendida de acordo com as novas perspectivas no âmbito da ampliação do campo do patrimônio, que se fundamentam nas interações entre os aspectos ambiental e cultural, material e imaterial. Para melhor compreensão da paisagem cultural, recorreu-se ao desenvolvimento das noções de lugar e de genius loci na esfera dos organismos internacionais e nacionais de patrimônio. Empreendeu-se uma reflexão sobre como identificar a imaterialidade das relações socioespaciais que se manifestam no lugar e na paisagem, com o intuito de contribuir para salvaguardar estas referências culturais.

Palavras-chave: Cultura. Lugar. Paisagem. Patrimônio.

\section{ABSTRACT}

This article aims to present the notion of cultural landscape according to the new perspectives related to the heritage expansion domain. Those perspectives are mainly based on the interactions among environmental and cultural aspects, as well among material and immaterial. For a better comprehension of cultural landscape, was examined the development of the notions of place and genius loci, in the scope of international and national establishments. Thus, a reflection was done about how to identify the immateriality of socio-spatial relations that manifest in place and landscape, with the intention of contribute to safeguard these cultural references.

Keywords: Culture. Place. Landscape. Heritage.

\section{INTRODUÇÃO}

O modo como representamos o espaço e o tempo na teoria importa, visto afetar a maneira como nós e os outros interpretamos e depois agimos com relação ao mundo. (HARVEY, 1992, p. 190).

Tempo e espaço são, para Kant (1999), formas puras de toda intuição sensível'. Jamais é possível fazer uma representação de que não haja espaço algum, embora se possa pensar que não se encontre nenhum objeto nele. Sendo, então, o espaço

Para Kant (1999), diversos tempos não são simultâneos, mas sucessivos; em contrapartida, diversos espaços não são sucessivos, mas simultâneos. Tempos diferentes são apenas partes do mesmo tempo; do mesmo modo, só se pode representar um espaço uno, que tudo compreende.

* Arquiteta e urbanista graduada pela Universidade de Brasília (UnB). Doutora em Geografia pela Universidade Federal de Santa Catarina (UFSC). Professora do Curso de Arquitetura e Urbanismo da UFSC.

soraya@arq.ufsc.br 
considerado a condição da possibilidade dos fenômenos e não uma determinação dependente destes.

Santos (1999, p. 51) explica a dinâmica e a transformação do espaço por meio do sistema de objetos e do sistema de ações:

O espaço é formado por um conjunto indissociável, solidário e também contraditório, de sistemas de objetos e sistemas de ações, não considerados isoladamente, mas como um quadro único no qual a história se dá.

Se considerarmos como objetos (geográficos) tudo o que há sobre a superfície da Terra, tanto os naturais, como os criados pela ação transformadora do homem, estaremos diante do sistema de objetos. "Os objetos são tudo que se cria fora do homem e se torna instrumento material de sua vida." (SANTOS, 1999, p. 59).

Por sua vez, as necessidades humanas, as quais podem ser materiais, imateriais, econômicas, sociais, culturais, morais ou afetivas, levam o homem a agir estabelecendo um sistema de ações, por meio da criação e do uso dos objetos geográficos (naturais ou sociais). O sistema de objetos condiciona a maneira como se dão as ações, e o sistema de ações realiza-se sobre os objetos existentes ou leva à criação de novos objetos.

Para o enfoque da presente reflexão, que busca maior compreensão do significado da paisagem cultural, com o intuito de colaborar com sua conservação², é particularmente elucidador ter em mente a interação entre os sistemas de objetos e de ações.

Ao procurar demarcações para compreender a sua complexidade, recorreu-se à ideia de que os aspectos materiais da paisagem cultural estão vinculados ao sistema de objetos - e que os aspectos imateriais, por sua vez, são advindos do sistema de ações, e podem ser apreendidos na manifestação do lugar, mais especificamente, do "espírito do lugar" (NÓR, 2010).

\section{PAISAGEM CULTURAL}

Paisagem cultural é um termo relativamente recente ${ }^{3}$, que tem comparecido com frequência crescente nas discussões de âmbito patrimonial. Buscou-se, neste artigo, empreender uma reflexão acerca de seus sentidos, associados também ao conceito espacial de lugar, considerado pertinente para a compreensão de sua abrangência. Destacam-se, a seguir, as sucessivas definições de paisagem cultural que constam das

\section{Cartas Patrimoniais ${ }^{4}$.}

Em 1995, o documento Recomendação da Europa aborda a paisagem cultural como:

Caracterizada pela maneira pela qual é percebida por um indivíduo, ou por uma comunidade, testemunhando, do passado ao presente, o relacionamento entre o

2 O termo conservação utilizado ao longo deste artigo aponta para uma dimensão mais abrangente, que o expressa pela ideia de preservação. A conservação considera a inevitabilidade da mudança com enfoque nas características que apresentam maior significação cultural (CASTRIOTA, 2009).

3 A categoria de paisagem cultural foi consolidada pelo Comitê do Patrimônio Mundial, em Santa Fé (EUA), em 1992. (CASTRIOTA, 2009).

$4 \quad$ Disponíveis em: <http://www.iphan.gov.br>. Acesso em: 23 mar. 2012. 
homem e seu meio ambiente. Possibilitando, a partir de sua observação, especificar culturas e locais, sensibilidades, práticas, crenças e tradições. (UNESCO. Recomendação da Europa, 1995).

Em 1999, a United Nations Educational, Scientific and Cultural Organization (UNESCO) ${ }^{5}$ definiu paisagem cultural da seguinte maneira:

Paisagens culturais representam o trabalho combinado da natureza e do homem [...] são ilustrativas da evolução da sociedade e dos assentamentos humanos ao longo do tempo, sob a influência das determinantes físicas e/ou oportunidades apresentadas por seu ambiente natural e das sucessivas forças sociais, econômicas e culturais, tanto internas, quanto externas. Elas deveriam ser selecionadas com base tanto em seu extraordinário valor universal e sua representatividade em termos de região geocultural claramente definida, quanto por sua capacidade de ilustrar os elementos culturais essenciais e distintos daquelas regiões. (UNESCO. Convenção do Patrimônio Mundial, 1999).

Em 2009, o Instituto do Patrimônio Histórico e Artístico Nacional (IPHAN) considerou como paisagem cultural brasileira "[...] a porção peculiar do território nacional, representativa do processo de interação do homem com o meio natural, à qual a vida e a ciência humana imprimiram marcas, ou atribuíram valores." (IPHAN, 2009)6 .

A partir destas definições, podemos verificar que houve uma ampliação no campo do patrimônio, na qual a paisagem cultural se fundamenta nas interações entre o homem e a natureza, na medida em que considera formas tradicionais de vida e de relação com o meio ambiente. (CASTRIOTA, 2009).

Além disto, os aspectos materiais e imateriais do patrimônio estão entrelaçados na concepção das paisagens culturais que congregam a vitalidade da cultura nas formas de produção da vida, que se expressam historicamente no lugar. A paisagem reúne formas criadas em momentos históricos diferentes, que coexistem no momento atual. Os testemunhos de um tempo passado incrustam-se na paisagem como uma rugosidade. (SANTOS, 1985).

No espaço, as formas-objeto que compõem a paisagem preenchem, no momento atual, uma função atual, como resposta às necessidades da sociedade:

A paisagem nos permite apenas supor um passado. Se quisermos interpretar cada etapa da evolução social, cumpre-nos retomar a história que esses fragmentos de diferentes idades representam juntamente com a história tal como a sociedade a escreveu de momento em momento. (SANTOS, 1999, p. 86).

Deste modo, em sua concretude material, a paisagem revela a importância de seu conteúdo histórico. A dualidade material e imaterial da paisagem cultural merece uma análise capaz de elucidar aspectos relevantes no esforço para sua conservação como referência cultural ou bem patrimonial.

\footnotetext{
5 UNESCO: United Nations Educational, Scientific and Cultural Organization (Organização das Nações Unidas para a Educação, a Ciência e a Cultura).

6 Portaria IPHAN n. 127, de 30 de abril de 2009. Estabelece a chancela da paisagem cultural brasileira.
} 
A apreensão, a percepção e a interpretação das paisagens são permeadas de subjetividade. Entretanto, nesta análise, pontuamos que a porção material da paisagem, em seus arranjos naturais ou produzidos pelo engenho humano, pode ser compreendida por sua configuração espacial, ou pelo "[...] conjunto de formas possível de abarcar com a visão." (SANTOS, 1999, p. 61). Sua porção imaterial, complementar, seria conferida pela dimensão social.

Para melhor compreender os aspectos subjetivos inerentes à paisagem cultural consideramos pertinente recorrer a outro conceito espacial, o de lugar e, em especial, no que tange à sua imaterialidade.

\section{PATRIMÔNIO IMATERIAL}

Entende-se por patrimônio cultural imaterial as práticas, representações, expressões, conhecimento e técnicas, junto com os instrumentos, objetos, artefatos e lugares que the são associados, que as comunidades, os grupos e, em alguns casos, os indivíduos, reconhecem como parte integrante de seu patrimônio cultural. (UNESCO. Convenção para a Salvaguarda do Patrimônio Cultural Imaterial, 2003).

Na definição de patrimônio imaterial, além destas características, destaca-se também seu caráter dinâmico, que, ao ser transmitido de geração a geração, é constantemente recriado, gerando um sentimento de identidade e de continuidade. A incorporação de valores simbólicos e imateriais trouxe para o âmbito patrimonial um caráter abrangente, que engloba ideias relativas a concepções de desenvolvimento e democratização da cultura. Quando são atribuídos valores culturais ao que transcende a matéria, depara-se com uma rede subjetiva de significados, que demanda critérios para elucidar sua articulação. Neste sentido insere-se nossa intenção de associar as categorias espaciais de paisagem cultural e de lugar.

$\bigcirc$ lugar passou a integrar a categoria de patrimônio imaterial ${ }^{7}$ por meio do reconhecimento de locais onde se concentram e se reproduzem práticas culturais coletivas referentes a grupos que, nestes espaços, efetuam trocas materiais e simbólicas. $\bigcirc$ Programa Nacional do Patrimônio Imaterial (PNPI) instituiu, para o registro destes bens, o Livro dos Lugares. (FONSECA, 2003).

$\mathrm{Na}$ nova concepção de lugar estão implícitos os laços sociais intangíveis que o conformam. Para eleger um lugar como bem cultural é preciso considerar a dimensão física e a social, associar os elementos tangíveis com os intangíveis. No campo do patrimônio, utilizava-se, tradicionalmente, a classificação de sítio histórico para identificar conjuntos de edificações, ruas e marcos físicos significativos.

Assim, a categoria de lugar como patrimônio imaterial significa a superação desta visão. Portanto, para constituir o patrimônio imaterial há que se considerar as pessoas

Decreto n $^{\circ} 3.551$, de 4 de agosto de 2000, instituiu as formas de registro de bens culturais de natureza imaterial ou intangível no Brasil. A Resolução IPHAN n. 1, de agosto de 2006, complementa o Decreto. As categorias de bens culturais passaram a incluir: saberes; celebrações; linguagens e espaços. (IPHAN, 2000). 
e os seus modos de vida. O lugar e a paisagem - como categorias do patrimônio cultural - constituem-se da mistura indissociável entre o material e o imaterial, posto que a conformação física estabelece uma relação dialética com o componente social. As práticas sociais dão sentido ao lugar, e o lugar é fundador de tais práticas. As vivências e as relações sociais manifestam-se na paisagem dos lugares. Estas relações se dão, também, por meio de uma sobreposição de ideias, crenças, valores e sentimentos vinculados à dimensão imaterial.

As discussões a respeito do patrimônio permeiam a questão da conservação, que se apresentava, até recentemente, mais afeita à dimensão física. Assim, surge um novo desafio, que consiste em como identificar e criar mecanismos de conservação para o que não é material. No âmbito da paisagem cultural, entendemos ser pertinente identificar e compreender o lugar e seu "espírito" por meio do reconhecimento dos componentes materiais e imateriais que os caracterizam. Estes podem ser essenciais para a preservação da identidade das comunidades que tenham produzido espaços e práticas culturais transmitidos através de gerações.

\section{A ESCALA DO LUGAR}

A sociedade produz uma hierarquia de escalas espaciais - como nações, Estados, comunidades, lugares, lares - com a qual organiza suas atividades e compreende seu mundo. O lugar configura-se, portanto, como uma escala espacial, em constante inter-relação com as demais escalas, na qual os seres humanos buscam a realização de suas metas e organizam seus comportamentos coletivos.

Podemos considerar o lugar como o espaço diferenciado (dos outros lugares) pela combinação específica de variáveis, representadas por seu meio ecológico, pelas possibilidades técnicas disponíveis e desenvolvidas, pelas relações sociais estabelecidas e pelos padrões culturais próprios. A peculiaridade de um lugar é constituída pela constelação de relações entre as variáveis, as quais se encontram e se entrelaçam num locus particular. (SANTOS, 1997; MASSEY, 2000).

Além deste aspecto, o lugar está intimamente associado ao mundo dos valores, mesmo que imaginários e simbólicos, sendo um elemento constitutivo dos grupos sociais, desempenhando um papel na estrutura dos indivíduos. Guardamos os lugares em nossas lembranças e emoções, podemos identificá-los com afetos e experiências de vida, o que faz com que os lugares compareçam na formação complexa das personalidades humanas. $\bigcirc$ lugar não pode, portanto, ser interpretado como um suporte neutro da vida social. (SANTOS, 1985; CLAVAL, 2007). O lugar pode ser apreendido por seu caráter identificador, que permite que seus habitantes se reconheçam e se definam por meio dele. $\bigcirc$ caráter relacional do lugar possibilita a percepção dos laços sociais que os habitantes mantém entre si. (AUGÉ, 1994).

Ao apresentar o sistema de ações, Santos (1999) considera três tipos de agir: o técnico, o formal e o simbólico. $\bigcirc$ agir simbólico compreende as formas afetivas, emo- 
tivas e rituais ${ }^{8}$. A força de transformação, de mudança, ou a recusa do passado vêm do agir simbólico, dos modelos de significação e representação. A importância do lugar na formação da consciência (dos indivíduos) vem do fato de que essas formas do agir são inseparáveis. Na construção do lugar observam-se variações locais de modos de vida, de estruturas de sentimentos, de formas de relacionamento social e de produção, de estruturas sociológicas e de valores e crenças. (HARVEY, 2004).

Deste modo, o conceito de lugar expressa uma clara identificação com grupos sociais definidos, contextualizando suas atividades. Entretanto, não se trata de uma visão idealizada ou estereotipada de comunidade, vista como um grupo coerente, homogêneo e isolado. Os lugares são constituídos por diferentes atores sociais, tanto por aqueles que os criam e habitam, como por aqueles que os visitam, todos participando ativamente da construção de seu sentido.

O lugar pode ser compreendido como a espacialização das relações sociais, sendo que todas elas interagem com a história acumulada do lugar e com o que lhe é externo. A relação do sujeito, ou do grupo social, com seu espaço de vida, passa por construções de sentido e de significado que se baseiam não somente na experiência direta e na prática funcional, mas também no valor simbólico conferido ao ambiente, construído pela cultura e pelas relações sociais.

A identidade dos lugares remete a dois aspectos importantes. Por um lado, está vinculada ao sujeito, às suas memórias, concepções, interpretações, às suas ideias e a seus afetos, sendo capaz de trazer sentimentos de segurança e bem-estar ao indivíduo. Por outro lado, a identidade pode emanar do próprio lugar, que se manifesta como seu "espírito", sendo possível reconhecê-lo e vivenciá-lo. Esta possibilidade nos auxilia sobremaneira na senda de compreender a categoria de paisagem cultural.

\section{O "ESPÍRITO DO LUGAR"}

No âmbito do lugar, identificar e compreender seu "espírito" facilita o reconhecimento dos componentes materiais e imateriais que o caracterizam. Essa abordagem nos remete à ideia histórica do genius loci, ou "espírito do lugar", divindade romana que presidia e identificava o centro de um lugar, ao mesmo tempo em que se desenvolvia e se fortalecia nesse local.

Na expansão do Império Romano, um sacerdote era encarregado de identificar o suposto local de permanência do "deus" no território recém-conquistado. Depois de encontrado, este passava a ser o ponto central de cruzamento dos eixos perpendiculares cardus e decumanus, que configuravam o traçado de um novo assentamento humano, passando a ser também um local sagrado, dedicado às oferendas. (ROSSI, 2001). Acreditava-se que o comportamento dos homens interferia nos poderes da divindade: se 0 "espírito do lugar" fosse negligenciado, seus moradores poderiam sofrer infortúnios, e, quando devidamente cultuado e reverenciado, ampliava-se sua capacidade de proteção.

O agir técnico é relativo às técnicas, e o agir formal refere-se aos formalismos jurídicos e econômicos. (SANTOS, 1999). 
Quando nos referimos, hoje, ao "espírito do lugar", tratamos do elemento vital que expressa a singular identidade de um local, resultado da relação entre uma determinada cultura e o sítio em que se desenvolve. Esta noção de "espírito do lugar" está intimamente vinculada à interação de componentes materiais e imateriais presentes nos ambientes naturais e nos espaços construídos.

No âmbito dos organismos internacionais de patrimônio, tem havido uma constante preocupação com a salvaguarda e promoção do "espírito dos lugares", sobretudo do seu caráter vivo e social, em especial, na esfera do Conselho Internacional de Monumentos e Sítios (ICOMOS)?

"espírito do lugar" consiste no conjunto de bens materiais (sítios, paisagens, edificações, objetos) e imateriais (memórias, depoimentos orais, documentos escritos, rituais, festivais, ofícios, técnicas, valores, odores), físicos e espirituais, que dão sentido, valor, emoção e mistério ao lugar, de tal modo que o espírito constrói o lugar e, ao mesmo tempo, o lugar constrói e estrutura o espírito. (ICOMOS. Declaração de Quebec, 2008).

Na sua dinâmica relacional com os demais planos escalares, o "espírito do lugar" incorpora, assim, um caráter plural e polivalente, com diferentes significações e singularidades, podendo mudar de sentido com o tempo e ser compartilhado por diferentes grupos.

Os componentes capazes de identificar o "espírito do lugar" estão presentes nos cenários da vida social e em suas manifestações simbólicas, bem como nos espaços apropriados ou construídos pelo homem, que expressam um modo particular de resolver as necessidades para o desenvolvimento da vida, através da história, conforme elucida Cozen (2009, p. 50):

Ao longo do tempo, a paisagem constituída por uma extensa região, como um país, ou por uma pequena localidade como um núcleo urbano adquire um específico "genius locci", que é a caracterização da sua cultura e da condição histórica que refletem igualmente não somente o trabalho e as aspirações da sociedade atual, mas, também, os que a precederam.

○ "espírito do lugar" deve ser compreendido como a essência de seus valores imateriais, que revela a relação dialógica entre passado e presente por meio das permanências. Desta forma, pode-se depreender que um lugar com "espírito" seja passível de ser considerado como bem cultural e possa vir a tornar-se parte do patrimônio imaterial de uma sociedade - e, também, que a noção de "espírito do lugar" confere o caráter ao mesmo tempo vivo e permanente às paisagens culturais.

\footnotetext{
9 O ICOMOS é uma organização de voluntários com atuação internacional, voltada para aperfeiçoar e aprofundar as questões relativas à defesa e valorização do patrimônio cultural. A cada três anos, a organização promove um simpósio científico, colocando determinado tema em debate. Em 2008, o tema foi o "espírito dos lugares". A Declaração de Foz do Iguaçu (encontro latino-americano preparatório para - Simpósio no Canadá) e a Declaração de Quebec inscrevem-se numa série de medidas e ações adotadas para sua preservação.
} 


\section{A CONSERVAÇÃO DAS PAISAGENS CULTURAIS}

A significação e a autenticidade das paisagens culturais envolvem o meio ambiente natural e também elementos que se relacionam com a dimensão imaterial do patrimônio, especialmente o sentido de lugar. Em lugares e paisagens, a materialidade e a imaterialidade são indissolúveis. A constituição dos lugares e paisagens é determinada pelo processo histórico e permeada pelos sentidos humanos a eles dados, os quais emanam de vivências e convivências (NÓR, 2010).

Assim, o lugar e a paisagem apresentam-se como categorias espaciais reveladoras dos modos de viver e conceber a vida, ancorados no processo histórico de produção e interação com o meio natural. Eles contribuem para a complexa construção das identidades culturais e, também, para a maneira de apreendê-las, relacionando-as a outras dimensões da vida social, com as quais estão direta ou indiretamente conectados.

$\mathrm{Na}$ evolução das noções de patrimônio no âmbito dos organismos internacionais e nacionais tem-se buscado instrumentos para promover a proteção e a preservação cultural, ampliando o leque do que se consideram bens culturais, assim como as referências para sua identificação.

Quando se vinculam às categorias espaciais com a noção de patrimônio emerge a preocupação com a salvaguarda da cultura por meio dos novos mecanismos e instrumentos para a preservação, a conservação e a gestão dos bens culturais, dentre os quais se destacam o lugar como patrimônio imaterial e a paisagem como cultural.

Considerou-se pertinente, apesar de se constatar amplas sobreposições em relação aos conceitos espaciais de lugar e paisagem, demarcar nuances mais apropriadas de análise.

No exame que nos propusemos realizar, o sentido de lugar parece ser mais adequado para compreender os grupos sociais e suas interações, ou o sistema de ações de Santos (1999). Já a paisagem, na qual está implícita a possibilidade de visualização, está mais identificada com o sistema de objetos, que é espacializado de acordo com o processo histórico.

Desta forma, a paisagem possibilita uma leitura do lugar e uma interpretação cultural, enquanto o lugar permite compreender a geografização de relações sociais específicas e diferenciadas, materializadas na paisagem.

Espera-se que esta demarcação conceitual possa auxiliar na identificação das especificidades do patrimônio imaterial, contribuindo para a sua valorização e conservação. 


\section{REFERÊNCIAS BIBLIOGRÁFICAS}

AUGÉ, Marc. Não-lugares: introdução a uma antropologia da supermodernidade. Campinas: Papirus, 1994. $111 \mathrm{p}$.

BRASIL. INSTITUTO DO PATRIMÔNIO HISTÓRICO E ARTÍSTICO NACIONAL - IPHAN. Patrimônio imaterial: o registro do patrimônio imaterial: dossiê final das atividades da comissão e do grupo de trabalho patrimônio imaterial. Brasília: IPHAN, 2000. 208 p.

Patrimônio imaterial. Disponível em: <http://portal.iphan.gov.br>. Acesso em: 23 jul. 2008.

Portaria n. 127, de 30 de abril de 2009. Estabelece a chancela da paisagem cultural brasileira. In: Diário Oficial da União, 5 de maio de 2009, n 83, p.17.

CASTRIOTA, Leonardo. Patrimônio cultural: conceitos, políticas, instrumentos. São Paulo: Annablume. Belo Horizonte: IEDS, 2009. 380 p.

CLAVAL, Paul. A geografia cultural. 3 ed. Florianópolis: Editora da UFSC, 2007. 453 p.

COZEN, Michael. As paisagens urbanas históricas na Inglaterra: um problema de geografia aplicada. In: CASTRIOTA, Leonardo. (Org.). Paisagem cultural e sustentabilidade. Belo Horizonte: IEDS; UFMG, 2009. p. 46-67. Coleção Arquitetura e Cidade - Coedição com a Editora UFMG. p. 46-67.

FONSECA, Maria Cecília Londres. Para além da pedra e cal: por uma concepção ampla de patrimônio cultural. In: ABREU, Regina; CHAGAS, Mário (Org.). Memória e patrimônio: ensaios contemporâneos. Rio de Janeiro: DP\&A, 2003, p. 56-76

HARVEY, David. Condição pós-moderna. 6 ed. São Paulo: Loyola, 1992. 349 p.

Espaços de esperança. São Paulo: Loyola, 2004. 382 p.

ICOMOS Brasil - Conselho Internacional de Monumentos e Sítios. Disponível em: <http://www.icomos.org.br>. Acesso em: 23 jul. 2008.

KANT, Immanuel. Crítica da razão pura. São Paulo: Nova Cultural, 1999.511 p. (Coleção Os Pensadores). ICOMOS Brasil - Conselho Internacional de Monumentos e Sítios. Disponível em: <http://www.icomos.org.br>. Acesso em: 23 jul. 2008.

MASSEY, Doreen. Um sentido global do lugar. In: ARANTES, Antonio Augusto. (Org.). O espaço da diferença. Campinas: Papirus, 2000, p. 177-185.

NÓR, Soraya. Paisagem e lugar como referências culturais: Ribeirão da llha - Florianópolis. 2010. 231 f. Tese (Doutorado em Geografia) - Curso de Geografia da Universidade Federal de Santa Catarina, Florianópolis, 2010.

ROSSI, Aldo. A arquitetura da cidade. São Paulo: Martins Fontes, 2001. 306 p.

SANTOS, Milton. Espaço e método. São Paulo: Nobel, 1985. 88 p.

Metamorfoses do espaço habitado. São Paulo: Hucitec, 1997. 124 p.

A natureza do espaço: técnica e tempo, razão e emoção. 3 ed. São Paulo: Hucitec, 1999. 308 p.

UNESCO. Recomendação da Europa, 1995. IPHAN. Cartas Patrimoniais. Disponível em:

<http://portal.iphan.gov.br>. Acesso em: 23 mar. 2012.

Convenção do Patrimônio Mundial, 1999. IPHAN. Cartas Patrimoniais. Disponível em:

<http://portal.iphan.gov.br>. Acesso em: 23 mar. 2012.

Convenção para a Salvaguarda do Patrimônio Cultural Imaterial, 2003. IPHAN. Cartas Patrimoniais.

Disponível em: <http://portal.iphan.gov.br>. Acesso em: 23 mar. 2012. 